\title{
Conflict Resolution Education:The Field, the Findings, and the Future
}

TRICIA S. JONES

( ver the past two decades, conflict resolution education (CRE) programs have educated children about constructive approaches to managing conflict in their schools and communities. CRE provides critical life skills necessary for building caring communities and establishing constructive relationships (Jones and Compton, 2003). Educators, administrators, and parents advocate CRE as a critical component to the development of safe and drug-free schools (Heerboth, 2000; King, Wagner, and Hedrick, 2001; Oppitz, 2003).

To sustain program development and funding of CRE, questions of efficacy are paramount. This is truer now more than ever before given the emphasis in the No Child Left Behind Act of 2001, which dictates that all instruction in academic and nonacademic areas (including prevention interventions) must be theoretically based and rigorously evaluated.

To what extent does CRE make the differences so hoped for by educators and parents? To what extent are CRE programs meeting the standards set under No Child Left Behind, and therefore worthy of federal support dollars? This article provides an answer within certain parameters. First, CRE is defined and distinguished from related efforts to clarify the nature of program evaluation research that should be included in this review. Second, structural elements that are expected to influence CRE effectiveness are detailed as a framework for the presentation of research. And third, the overall assessment of CRE field research is used as a foundation for discussion of needed future research.

\section{The Field of Conflict Resolution Education}

Conflict resolution education "models and teaches, in culturally meaningful ways, a variety of processes, practices and skills that help address individual, 
interpersonal, and institutional conflicts, and create safe and welcoming communities" (Association for Conflict Resolution, 2002, p. 1). Conflict resolution education programs provide students with a basic understanding of the nature of conflict, the dynamics of power and influence that operate in conflict, and the role of culture in how we see and respond to conflict.

CRE programs are estimated to be in place in fifteen thousand to twenty thousand of our nation's eighty-five thousand public schools. Several states, including Ohio, Oregon, New Mexico, and Indiana, have made significant progress on statewide implementation of conflict resolution education (Batton, 2002; Ford, 2002; Tschannen-Moran, 2001).

\section{Goals of Conflict Resolution Education Programs}

Four broad goals are discernable through the CRE literature. Each goal suggests outcomes that may be monitored to evaluate CRE effectiveness.

Create a Safe Learning Environment. In the 1990s, one of the National Education Goals stated, "All schools in America will be free of drugs, violence and the unauthorized presence of firearms and alcohol, and will offer a disciplined environment that is conducive to learning" (U.S. Department of Education, 1998, p. 1). In response to that goal, Congress passed the Safe and Drug-Free Schools and Communities Act of 1994, which funded the Safe and Drug-Free Schools unit in the U.S. Department of Education. Since its inception, that office has sought to develop, implement, and monitor initiatives that can help create safe learning environments in schools. Among those initiatives are conflict resolution education programs (Cuervo, 2003). Programs that emphasize this goal are interested in the following kinds of outcomes:

- Decreased incidents of violence

- Decreased conflicts between groups of students, particularly intergroup conflicts based on racial and ethnic differences

- Decreased suspensions, absenteeism, and dropout rates related to unsafe learning environments

Create a Constructive Learning Environment. Teachers and administrators know that learning cannot take place without a constructive learning environment for students—one with a positive climate, effective classroom management, and a respectful and caring environment where children feel safe to share ideas and feelings (Lieber, 2003). Teachers often wrestle with 
classroom management and classroom discipline (Girard and Koch, 1996; Kohn, 1996; Weiner, 1999), especially in urban education environments (Feiman-Nemser, 2003; Shann, 1998). For this goal expected outcomes include:

- Improved school climate

- Improved classroom climate

- Increased respectful and caring environment

- Improved classroom management

- Reduced time that teachers spend on disciplinary problems in the classroom

- Increased use of student-centered discipline

Enhance Students' Social and Emotional Development. At the heart of all CRE is the hope of helping children to develop as better people - to be more socially and emotionally competent so that they can lead happier lives and contribute more positively to society (Kessler, 2003). If this is achieved, the logic is that other CRE goals will also be accomplished (Lantieri, 2001).

It is in the pursuit of this goal that CRE programs most often overlap with social and emotional learning programs (Lantieri and Patti, 1996). When CRE is effective in achieving this goal, the benefits include outcomes like these:

- Increased perspective taking

- Improved problem-solving abilities

- Improved emotional awareness and emotional management

- Reduced aggressive orientations and hostile attributions

- Increased use of constructive conflict behaviors in schools and in home and community contexts

Create a Constructive Conflict Community. Creating a constructive conflict community requires developing and advocating for social justice. A constructive conflict community is also one in which there is a shared responsibility for social ills and social accomplishments. In such a community, destructive conflict is seen as something the community needs to address. This is one of the basic assumptions underlying the notion of restorative justice approaches to CRE (Ierley and Claassen-Wilson, 2003). 
Success in creating a constructive conflict community would be evident in outcomes including the following:

- Increased parental and community involvement in school affairs

- Increased links between school CRE and community CRE efforts

- Decreased community tension and violence

\section{Conflict Resolution Education and Related Fields}

At its inception, CRE was narrowly focused on the application of mediation models to $\mathrm{K}-12$ populations. Yet in the past twenty years, the field has expanded in form and function, an expansion that has increased its potential as much as it has obscured its boundaries. Today CRE overlaps with a number of related fields like peace education, violence prevention, social and emotional learning, and antibias education.

Peace Education. Salomon (2002, p. 7) describes peace education as including ". . . antiracism, conflict resolution, multiculturalism, crosscultural training and the cultivation of a generally peaceful outlook." According to Sommers (2003), peace education helps develop communication skills of active listening and assertive speech, problem-solving skills of brainstorming or consensus building, and orientation skills of cultural awareness and empathy. CRE and peace education are similar in terms of basic motivations, goals, key skills, and content. Yet CRE is domestically applied and peace education is internationally applied, and peace education has a stronger emphasis on social justice orientations and larger systemic issues of violence than conflict education programs.

Violence Prevention. Violence prevention programs often include a CRE component, but are more likely to include increases in safety and security issues relevant to the prevention of serious violent behaviors that are, luckily, still quite rare in schools (Burstyn and others, 2001). Violence prevention efforts seek to decrease serious risk behavior, including violence toward self and others, risky sexual behavior, and substance abuse (Wilson, Gottfredson, and Najaka, 2001). CRE is focused more on the development of important life skills that help students find nonviolent ways to handle their problems and thereby may decrease violent behavior.

Social and Emotional Learning. CRE and social and emotional learning (SEL) programs help students develop emotional, cognitive, and behavioral competencies (Elias and others, 1997). Conflict resolution educators heartily endorse the following suggested competencies articulated by the 
Collaborative for Academic, Social and Emotional Learning (CASEL, 2002). In the emotional domain, students should learn to identify emotions, control anger, manage frustration, and respect others' feelings. In the cognitive domain, students should develop the ability to take the other's role or perspective, problem-solve, set goals, and cooperate. In the behavioral domain, students should build interpersonal skills necessary for positive social interaction, including negotiating disputes, taking responsibility for actions, managing time, respecting others' space, and appreciating social norms. The differences in CRE and SEL are becoming harder to identify as the fields truly integrate.

Antibias Education. Many people have argued convincingly that CRE does and should overlap with antibias education because prejudice is an underlying cause for conflict, and we need to realize the impact of prejudice on schools and communities (Lantieri and Patti, 1996; Oskamp, 2000). Most antibias education efforts fall into one of the following four categories: cross-cultural awareness, prejudice reduction and appreciation for diversity, hate crime prevention, and examining the systemic roots of oppression to dismantle them.

\section{The World of CRE}

As Jones and Compton (2003) articulate, CRE encompasses a number of programs and practices. The substantive and developmental foundation of CRE is enhanced social and emotional competencies through SEL (Elias and others, 1997), with particular emphasis on emotional awareness, empathy and perspective taking, strategic expression, and cultural sensitivity. These competencies are often delivered through specific curricula like Second Step in early elementary years. A second foundational tier is the integration of conflict education in ongoing curricula like language arts, social studies, math, and science (Compton, 2002), a development heralded as critical to the institutionalization of CRE (Batton, 2002). Additional content-specific curricula are taught in general or in programmatic areas such as negotiation skills (Druliner and Prichard, 2003). And targeted programs address specific problems like bullying (Title, 2003), peer harassment (Juvonen and Graham, 2001), and bias-related conflicts (Prutzman, 2003; Smith and Fairman, 2004). The processes in which students and adults are educated include peer mediation (Cohen, 2003), dialogue (Johnson, Johnson, and Tjosvold, 2000), use of expressive arts (Conte, 2001), and restorative justice (Ierley and Claassen-Wilson, 2003). 
Given the scope of CRE, there are certain parameters that were used in this review. Although CRE initiatives take place in arenas outside schools, like after-school programs (Whittall, 2003) and juvenile justice facilities (Stewart, 2002), this article focuses exclusively on in-school CRE. There are exciting CRE and peace education efforts outside the United States (Harris and Morrison, 2003), but this review concentrates exclusively on CRE practice in the United States. And finally, although the span of CRE is from preschool to higher education and although valuable research has demonstrated the effectiveness of CRE in these age groups (Sandy and Boardman, 2000; Warters, 1995, 2000), this review will focus on $\mathrm{K}-12$ regular and special needs populations.

\section{Research on Conflict Resolution Education}

There has been a great deal of research on CRE, making decisions about focus and boundaries in a research review article a challenge. First, previous literature reviews and generic meta-analyses are presented briefly. These resources are helpful and reduce the need to re-report what has already been described, but they have weaknesses. Most of the earlier reviews group studies with very little discussion of how structural elements of the CRE program are related to implementation processes or outcomes. And given the intense interest in reduction of violence, many reviews focus heavily or exclusively on studies that have outcome measures related to violent acts or violent orientations (Wilson, Gottfredson, and Najaka, 2001). The most egregious example is the U.S. Surgeon General's Report on Youth Violence (2001), which identifies peer mediation as ineffective. Since 2001, this report has been cited by CRE critics and uninformed administrators as "proof" that schools should not implement CRE. Yet this conclusion must be understood in terms of the report's focus on looking at "effectiveness" solely in terms of whether the program prevented serious physical violence (such as murder, stabbing, or shooting). In addition, many of the review articles are somewhat outdated, especially given the amount of published and unpublished research on CRE in the past five years.

Second, key structural elements of CRE are detailed: program types or models, educational level, target population, and implementation specifics. These provide the framework for the review of specific research studies. 
Third, the review of research is presented. The emphasis is on providing a balance between methodological detail and practical insight based on differences that make a difference.

\section{Earlier Reviews and Meta-Analyses in CRE and SEL}

There are solid general reviews of CRE and SEL that readers will find valuable. Johnson and Johnson (1996a) focused primarily on peer mediation programs and conflict education within a cooperative learning context. The review reports positive findings for efficacy of peer mediation and conflict education, particularly on increases in students' conflict knowledge, self-reported prosocial behavior, and negotiation skills and positive impacts on classroom climate.

In 2000, Sandy and Cochran published a review chapter in The Handbook of Conflict Resolution that discusses the evidence in support of SEL and conflict education programs for children in preschool through high school. Of the general review pieces, it provides the most detail on preschool interventions and gives an excellent summary of the Peaceful Kids ECSEL (Early Childhood Education Social and Emotional Learning) Program the authors developed and evaluated at Columbia University Teachers College. ECSEL educates teachers and parents to model and teach emotional awareness, cooperative skills, empathy and perspective taking, and problem solving to preschool children. Sandy and her colleagues reported significant increases in children's assertiveness, cooperation, and self-control and significant decreases in aggressive, withdrawn, and moody behaviors. Preschool staff were able to independently integrate the skills in the class, and parents increased in authoritative (as opposed to authoritarian) parenting practices (Sandy and Boardman, 2000).

In the general CRE area, the most comprehensive review is Does It Work? The Case for CRE in Our Nation's Schools (Jones and Kmitta, 2000). This book summarizes the results of the CRE research symposia sponsored by the U.S. Department of Education and convened by the Conflict Resolution Education Network in March 2000. Teams of researchers, educators, and CRE practitioners reviewed research on five topic areas: impact on students, impact on educators and teachers, impact on diverse student populations, impact on school climate, and issues of institutionalization. CRE programs increase students' academic achievement, positive attitudes toward school, assertiveness, cooperation, communication skills, healthy interpersonal and intergroup relations, constructive conflict resolution at 
home and school, and self-control. It decreases students' aggressiveness, discipline referrals, dropout rates, and suspension rates. There is little research on the effects of CRE on teachers. There is substantial evidence that CRE improves school climate (especially for elementary schools) and classroom climate. This book attests to the woeful lack of research on CRE and diverse and nondominant populations. Measures of success do not include diversity-relevant outcomes (impact on intergroup relations or community harmony is largely ignored), and issues of class or socioeconomic status receive very little attention. However, there is evidence that CRE programs that focus on systemic bias or include "contact theory" can improve intergroup relations (see Pettigrew and Tropp, 2000).

Does It Work? has strengths and weaknesses. The multiple perspectives on the research afforded by writing teams of researchers, practitioners, and educators provide insights often unavailable from exclusively researcherdriven reviews. Looking at CRE more broadly than individual outcomes for students or climate outcomes for schools is valuable as much for what it shows is missing as for what it suggests might be found. The weaknesses of the volume include its emphasis on reporting all the research rather than the best research, and the committee-determined format of structuring review chapters around hypotheses that impaired readability.

In the area of SEL, three review articles are noteworthy. Weissberg and Greenberg (1998) provide a comprehensive review of SEL programs and violence prevention programs, arguing for the efficacy of SEL programs on the development of core emotional competencies, especially for younger children. In 2003, Greenberg and colleagues reviewed schoolbased intervention and youth development initiatives and concluded that programs in this area are most beneficial when they simultaneously enhance students' personal and social assets as well as improve the quality of the environments in which students are educated. They cite a metaanalysis of 161 positive youth development programs (Catalano and others, 2002) that indicates SEL programs make a difference in improvements in interpersonal skills, quality of peer and adult relationships, and academic achievement, as well as reductions in problem behaviors such as school misbehavior and truancy, violence, and aggression. Greenberg and colleagues (2003) argue that skills-building components and environmental change initiatives are critical; optimal delivery of programs is through trained teachers who integrate the concepts into their regular teaching and do so over a longer period of time (six to nine months). 
For many educators faced with teach-to-the-test pressures, questions of academic achievement are uppermost. Zins, Weissberg, Wang, and Walberg (2004) provide valuable evidence that programs that enhance students' social-emotional competence foster better academic performance. When students are more self-aware and emotionally connected, they can focus on academics and achieve in a supportive environment.

\section{Structural Elements of Conflict Resolution Education}

What structures of CRE initiatives - that is, which programmatic and policy elements - are identifiable as sources of possible variation in impact? This article concentrates on four structural elements, with additional refinement of relevant structural components discussed within these general categories: program model, educational level, target population, and implementation characteristics.

Bodine and Crawford (1998) identified four program models of CRE: the mediation program approach, the process curriculum approach, the peaceable classroom approach, and the peaceable school approach. Although changes in program models are apparent since the creation of this taxonomy, it is still a useful distinction. The mediation program approach includes the use of peer mediation programs, in which students receive training in mediation and mediate disputes among their peers. In the process curriculum approach, students are taught the conflict curriculum as a separate course, a distinct curriculum outside regular class time or as a daily or weekly lesson in a related content curriculum. The peaceable classroom approach is a whole-classroom methodology that incorporates CRE into the core subjects of the curriculum and into classroom management strategies. This model includes what others have termed "curriculum infusion" (Poliner, 2003). The peaceable school approach is a comprehensive whole-school methodology that builds on the peaceable classroom approach by using conflict resolution as a system of operation for managing the school as well as the classroom. Conflict resolution principles and processes are learned and used by all members of the school (including parents). Also called whole-school programs, they often combine peer mediation with additional training and intervention efforts to provide the whole school with information to improve conflict behavior and develop key social and emotional skills.

The second structural factor, which will be treated here as nested within the program model factor, is educational level. CRE efficacy is 
influenced by use in elementary, middle, or high school contexts. The most obvious reason to distinguish educational level is the social and cognitive development of students (Selman, 1980). Younger students experience conflict differently and have different abilities to process conflict and its management (Jones and Brinkman, 1994). The second reason is the difference in organizational complexity between elementary, middle, and high schools. Elementary schools are smaller in size, more connected in terms of staff relationships, and more accessible to parent and community involvement than secondary schools. Middle schools, often a hotbed of interpersonal conflicts due to students' physical maturation and increasing peer pressures (Crosse and others, 2002), are much larger and shift from a classroom learning structure to a subject-based course learning structure. High schools, often as large as thirty-five hundred students, are extremely complex structures, often divided into smaller internal houses or learning communities to counteract the enforced anonymity and lack of support in the larger, bureaucratic structure (Hoy, Tarter, and Kottkamp, 1991). CRE efforts developed for and successful in one educational level can be dismal failures at another level.

The third structural factor is the target population for the CRE intervention. There are possible dimensions of difference that can be important: ability (in terms of special needs, at-risk, or regular populations), ethnicity, or gender. Of course, target populations may include adult staff and parents, as well as students.

The fourth structural factor is the implementation of CRE. First, there is the question of fidelity: To what extent is the CRE program or practice being implemented as designed? Second is the question of durability: To what extent is the CRE maintained over time? And third is the question of coordination with existing school structures (for example, discipline structures) and other CRE components - the issue of dispute system design.

\section{Research on CRE}

The research reviewed met the following criteria (similar to those used in Wilson, Gottfredson, and Najaka, 2001): (1) it evaluated a distinct intervention, program, or practice within the area of CRE as previously defined; (2) the intervention was school based, conducted in a school building, by school staff, or under school auspices; (3) it used a comparison group evaluation methodology, including nonequivalent comparison group research designs, and the comparison group was a no-treatment or minimaltreatment condition; (4) it had adequate sample size; and (5) it measured 
at least one of the outcomes relevant to CRE goals discussed earlier. In addition, all attempts were made to locate and review research that had not been included in earlier reviews, with special attention to unpublished reports from funded projects and dissertations.

In some program areas there are meta-analyses specific to that type of CRE. Sections reviewing research in that area begin with a brief discussion of those meta-analyses.

Peer Mediation. Peer mediation is the oldest and most common CRE intervention (Cohen, 2003). The National Association for School Principals reports that 75 percent of principals say they have some form of violence prevention or CRE and that peer mediation is the most common form (Cohen, 2003).

Burrell, Zirbel, and Allen (2003) conducted a meta-analysis on fortythree studies published between 1985 and 2003 of peer mediation programs that met the following criteria: (1) focused on K-12 student population, (2) used quantitative methods resulting in numerical measurable effects, and (3) involved at least one variable relating to mediation training or practices in which outcomes of the actual training or practices were measured. The results overwhelmingly support peer mediation effectiveness in terms of increasing students' conflict knowledge and skills, improving school climate, and reducing negative behavior.

When we look at peer mediation research linked to structural factors, can we obtain even more insight about the effectiveness of peer mediation? Specifically, are peer mediation programs equally effective across educational levels? To refine the analysis, it is important to examine the model of peer mediation used as well as the educational levels.

Structurally, peer mediation programs differ in terms of the training delivery and the program implementation, as well as educational level and linkage with other CRE components. These models can be labeled cadre, curriculum or class linked, or mentoring. In cadre peer mediation programs, student mediators are trained outside of classes and mediate disputes in a private area designated for that purpose. In curriculum or class-linked peer mediation, students in a classroom receive training in integrative negotiation and simple mediation process skills, rotate as mediators, and conduct mediations in class when requested by the teacher or peers in dispute. Mentoring peer mediation models involve student mediators' training younger students as peer mediators within the same school or across educational levels. While cadre peer mediation programs exist at all educational levels, curriculum or class-linked models are most common 
in elementary school, and mentoring models are most common in secondary schools (with middle school or high school mentors serving as elementary school mediators).

- Peer mediation research in elementary schools. Some early studies do not specify the model of peer mediation used. These studies also tend to focus on program utility outcomes (number of mediations, percentage of agreements reached) or basic knowledge indexes (whether the student learned mediation skills or negotiation skills). In these studies, thirdthrough sixth-grade students trained as mediators demonstrated significant increases in their use of integrative negotiation behaviors after mediation training. In addition, there was a high percentage of mediations reaching agreement (although simplistic agreements were the norm) (Johnson and Johnson, 1996b, 2001a), and there was some initial evidence that mediators may transfer their constructive conflict skills to sibling conflicts at home (Gentry and Benenson, 1992).

- Cadre models. Most peer mediation evaluation in elementary schools concerns cadre programs and concentrates on impacts of peer mediation on the mediators. Studies report that compared to nonmediators, mediators demonstrated increased knowledge of constructive conflict resolution (Korn, 1994; Nance, 1996), were able to mediate successfully (Johnson and colleagues, 1995), and demonstrated observable mediation skills (Winston, 1997). Research even suggests effectiveness for special needs students. Meyer's dissertation (1996) research examined the impact of participation in a peer mediation program on self-perceptions and conflict styles of behaviorally at-risk students. The pretest, posttest control group design using fourth- through sixth-grade subjects found no impacts on perception of self-worth or conflict style, but did find reductions in disciplinary referrals for mediators as compared to nonmediators.

Several studies examined the impact of peer mediation experience in the development of social and emotional competencies of mediators. Some research confirms positive impacts of peer mediation on disciplinary referrals, but fails to find differences between mediators and nonmediators on self-concept or social skills as measured by the Social Skills Rating System (Zucca-Brown, 1997). Conversely, Epstein (1996), using the same basic design and the same measure, reported that mediators had a larger increase in social skills than did disputants or control students.

Three studies investigated the impact of peer mediation on perspective taking. In his dissertation, Mankopf (2003) hypothesized that mediators 
would have better perspective taking, negotiation ability, attitudes toward fighting, and connectedness to school and family than nonmediators and that mediators who mediated more would demonstrate greater developmental gains. He found partial support for these hypotheses: mediators did score higher on perspective taking and negotiation ability, although experience did not play as much of a factor as anticipated. Lane-Garon (1998) studied the impact of peer mediation on cognitive and affective perspective taking of mediators and disputants. A total of 112 students (62 mediators and 50 nonmediators) in grades 4 through 8 were administered perspective-taking measures over the course of an academic year. Both mediators and disputants showed a significant increase in cognitive and affective perspective taking, but mediators' scores were significantly higher than disputants. In a second study, Lane-Garon (2000) examined the impact of peer mediation on cognitive perspective taking, strategy choice, and school climate. Her design compared mediators and nonmediators, by gender and ethnicity, from pretest to posttest. Eighty students in grades 4 through 6 served as subjects. The results show significant increases in mediators' perspective taking and selection of problem-solving conflict strategy. She also found ethnic differences, with African American participants (both mediators and nonmediators) showing the greatest increase in perspective taking and Hispanic participants showing the greatest positive change in conflict strategy choice when compared to Anglo participants.

- Curriculum or class linked. Most of the research in class-linked peer mediation comes from the Teaching Students to be Peacemakers Program (TSPP) developed by David and Roger Johnson at the University of Minnesota. TSPP creates a cooperative learning context, instructs students in integrative negotiation and mediation skills and concepts, and uses in-class peer mediation sessions. Teachers are trained to deliver the TSPP lessons (Fitch and Marshall, 1999).

Johnson and Johnson (2001b) conducted a meta-analysis of seventeen evaluation studies examining TSPP effectiveness in eight schools in two countries. Students ranged from kindergarten to grade 9 and were from urban, suburban, and rural schools. The results indicated that students learned the conflict resolution procedures taught, retained their knowledge throughout the school year, applied the knowledge to actual conflicts, transferred skills to nonclassroom and nonschool settings, and used the skills similarly in family and school settings. In addition, some of the studies revealed that exposure to TSPP increased academic achievement and decreased discipline referrals and classroom management problems. 
Although not included in the meta-analysis, two earlier TSPP studies (Johnson and Johnson, 1996c; Johnson and others, 1995) showed similar results in terms of students' conflict knowledge and tendency toward integrative negotiation in hypothetical and actual conflicts.

Two other studies investigated class-linked peer mediation using the community boards model and applied in playground mediations. Hart and Gunty (1997) used a nonequivalent control group design to study fourth- through sixth-grade mediators and found that the number of student conflicts and the average time-off-teaching per conflict decreased significantly in the classroom. However, Miller (1995) examined mediators and disputants on self-concept and used teacher and parent ratings of student behavior (Behavior Dimensions Rating Scale) and found no differences on any dependent measures.

- Mentoring peer mediation. A relatively recent and exciting approach to peer mediation is the mentoring model in which older students trained as mediators mentor younger students. One of the best programmatic examples is the Winning Against Violent Environments (WAVE) programs developed by Carole Close and institutionalized in the Cleveland Municipal School District. Bickmore (2002) evaluated twenty-eight urban elementary schools in which WAVE high school mediators trained twenty-five to thirty elementary mediators in each school, conducted follow-up visits with schools, presented at school staff meetings, and led workshops for parent groups. Data were collected on the understanding of conflict, attitudes toward conflict, perceptions of school climate (using the Students Attitudes About Conflict survey), attendance rate, number of suspensions, and academic achievement (in terms of Ohio Proficiency Tests of reading and citizenship). The results indicate that peer mediation has significant positive results for mediator and nonmediator attitudes about conflict, understanding of conflict, and perceptions of school climate. The mediators tended to have more significant increases on these measures than nonmediators, but this varied by experience level. In schools where the mediation program was inactive, the mediators did not score higher on these indices than nonmediators. Suspension rates were considerably reduced in the WAVE schools, and academic achievement scores increased in WAVE schools considerably more than the district average.

Lupton-Smith (1996) also examined a mentoring program using high school mentors, but focused on whether the mentoring experience affected the high school mediators' moral reasoning and ego development. The 
nonequivalent control group design compared mentors with other high school students involved in peer helping activities. The study found no significant differences, a finding perhaps attributable to the selection of a "helping" comparison group.

Lane-Garon and Richardson (2003) report on a cross-age mentoring mediation program in which university students served as mentors to elementary school mediators. Impacts on elementary students' cognitive and affective perspective taking, perceptions of school climate, and academic performance were assessed. The results show strong support for the impact of peer mediation on increases in mediators' cognitive and affective perspective taking and perceptions of school climate (especially in the area of perceived school safety).

Peer Mediation Research in Middle Schools. There is less research on the effectiveness of peer mediation programs in middle or high schools. This makes sense since peer mediation programs are implemented predominantly in $\mathrm{K}-6$ populations. The available research reports on cadre and class-linked programs in middle schools. No evaluations of mentoring programs were found.

- Cadre models. The research on these programs reports findings consistent with those in elementary school cadre models, even though middle school students are somewhat more cynical in general about peer mediation (Robinson, Smith, and Daunic, 2000). Mediators in middle school cadre programs, when compared with nonmediators, increase their knowledge of constructive conflict and indicate they will use those approaches (Bell and others, 2000; Stewart, 2000). These students, even very aggressive ones, also increase their self-esteem and self-concept (Fast, Fanelli, and Salen, 2003).

- Curriculum or class-linked programs. Once again, and as included in the TSPP meta-analysis, specific research in middle schools using the TSPP program reports that students in sixth through ninth grades benefit from this experience; they gain knowledge about conflict processes, increase their willingness to use integrative negotiation, and have more positive attitudes toward conflict (Dudley, 1995; Dudley, Johnson, and Johnson, 1996; Johnson and Johnson, 1997). However, this research does not demonstrate a positive impact of peer mediation on classroom climate.

Stevahn, Smith, Daunic, Miller, and Robinson (2002) conducted an evaluation of a curriculum-linked peer mediation program in three middle schools over a four-year period. The curriculum was taught schoolwide by 
teachers, but not all students received mediation training. There was no evidence of improvement in students' or teachers' perceptions of school climate, perhaps due to implementation problems since some teachers did not complete the curriculum in their classes. There were no differences between mediators and nonmediators on any of the dependent measures.

Farrell and his colleagues have found some impressive results from their Responding in Peaceful and Positive Ways (RIPP) program developed for urban middle schools that serve a predominantly African American student population. RIPP is a twenty-five-session social-cognitive conflict education curriculum, with problem solving the major focus of the curriculum; it includes a peer mediation component (Farrell, Meyer, Kung, and Sullivan, 2001). In one evaluation of RIPP with classes of sixth graders at three urban middle schools, students were randomized to intervention $(N=321)$ and control groups $(N=305)$. RIPP participants had fewer disciplinary violations and in-school suspensions than control students, an impact that lasted for twelve months after program implementation (Farrell, Meyer, and White, 2001). In one middle school, RIPP-6 was implemented and outcomes assessed using a battery of measures completed by students at pretest, posttest, and one-year follow-up. Compared with students in the comparison group, students who participated in RIPP-6 reported significantly lower approval of violent behavior, more peer support for nonviolent behaviors, less peer pressure to use drugs, and greater knowledge of the intervention at posttest. They also reported significantly lower posttest frequencies of physical aggression, drug use, and peer provocation (Farrell, Valois, and Meyer, 2002).

Peer Mediation Research in High Schools. As with middle schools, the peer mediation evaluation research concerns only cadre or curriculum-linked programs.

- Cadre models. In general, the research in this area is not supportive of peer mediation. Nelson (1997) studied the impact of mediation on selfesteem, social skills, and frequency of disciplinary referrals, but found no differences between the mediators and the control students, although these findings may be attributable to an inadequate sample size $(N=51)$. Sweeney (1996) was interested in whether mediation affected moral reasoning, orientations to others, and self-esteem; no significant differences were found between mediators and controls.

Potts's dissertation research (2002) shows more promising results. She examined the impact of mediation on interpersonal negotiation strategies 
(a measure of perspective taking and social problem solving) and coping styles. She compared mediators, disputants, and controls and found that mediators demonstrated higher levels of social competence and that more experienced mediators had the highest levels. Tolson and McDonald (1992) reported that students with high disciplinary referrals sent to mediation had significantly fewer referrals than students sent to traditional disciplinary processes.

- Curriculum or class-linked models. Stevahn and her colleagues have contributed the research in this area, although only one study deals with U.S. schools (Stevahn, Johnson, Johnson, and Schultz, 2002). Classes were randomly assigned to receive a five-week conflict curriculum with peer mediation or act as control groups. As in similar studies in elementary and middle schools, the results strongly confirm that training increased student knowledge of conflict and use of integrative negotiation. A very important outcome was that classes with the conflict resolution and peer mediation training also had higher academic achievement, greater long-term retention of academic learning, and greater transfer of academic learning in social studies to language arts.

Comparative Research in Peer Mediation. Only one study has compared different models of peer mediation across educational levels on individual student and school outcomes. The Comprehensive Peer Mediation Evaluation Project (Jones and others, 1997) involved twenty-seven schools in three communities (Philadelphia, Laredo, and Denver). In each community a $3 \times 3$ field experiment compared program models (peer mediation cadre programs, peer mediation curriculum-linked whole-school programs, and control schools) in each of three educational levels: elementary, middle, and high school. This study was guided by four research questions:

- Does peer mediation have an impact on students' conflict attitudes and behavior in terms of how frequently they are involved in conflict, how frequently they help others who are in conflict, their values about prosocial behavior in general, their conflict styles, their tendency toward aggressive behavior, their development of perspective taking and collaborative conflict orientations, or their ability to demonstrate or enact the skills taught in training?

- Does peer mediation have an impact on teachers' and students' perceptions of school climate?

- Are cadre programs better than whole-school programs (or vice versa)? In terms of impact on students' attitudes and behaviors, 
school climate, and program utility, is there a difference in the efficacy of these program models?

- Are peer mediation programs equally effective (or ineffective) for elementary, middle, and high schools?

All peer mediation schools (cadre and whole school) received peer mediation training and program implementation at the beginning of fall semester of each year. Schools receiving whole-school programs had curricular infusion training and conflict skills training by the end of fall semester.

Data were collected over two years. The sample consisted of multiple responses from each of the following (approximate numbers used):

- For elementary schools: 140 peer mediators, 1,300 control students, 400 conflict training students, and 275 teachers and administrative staff

- For middle schools: 140 peer mediators, 1,600 control students, 550 conflict training students, and 400 teachers and administrative staff

- For high schools: 150 peer mediators, 2,500 control students, 450 conflict training students, and 550 teachers and administrative staff

Thus, the overall sample consisted of 430 peer mediators, 5,400 control students, 1,400 conflict training students, and 1,225 teachers and administrative staff.

The data from the CPMEP study reveal that peer mediation programs provide significant benefit in developing constructive social and conflict behavior in children at all educational levels. It is clear that exposure to peer mediation programs, whether cadre or whole school, has a significant and lasting impact on students' conflict attitudes and behaviors. Students who are direct recipients of program training have the most impact, although students without direct training also benefit. The data clearly demonstrate that exposure to peer mediation reduces personal conflict and increases the tendency to help others with conflicts, increases prosocial values, decreases aggressiveness, and increases perspective taking and conflict competence. Especially for peer mediators, these impacts are significant, cumulative, and sustained for long periods. Students at all educational levels trained in mediation are able to enact and use the behavioral skills taught in training. 
The CPMEP results prove that peer mediation programs can significantly improve school climate at elementary levels, but the impact in middle and high schools is not significant, possibly due to limited diffusion capability in larger organizational environments. Similar results were obtained from a much smaller comparative study in the Dallas Public Schools (Nelson-Haynes, 1996), which found that peer mediation programs have a positive impact on student perceptions of school climate in elementary but not secondary schools.

Process Curricula. Process curricula are reviewed in terms of specific SEL curricula, negotiation and general conflict curricula, and bullyingprevention curricula. No research meeting the review criteria was found for bias awareness programs, dialogue programs, restorative justice, or expressive arts programs in CRE.

- SEL curricula. Two SEL curricula have been selected for mention in this section because they have strong overlap with CRE.

The PATHS Program is a classroom-based curriculum implemented by teachers for elementary grades (Kusche and Greenberg, 1995) and is effective for regular and special needs students (learning disabled or emotionally disturbed) (Greenberg and Kusche, 1996). PATHS helps children develop problem-solving, self-control, and emotional regulation skills. The program consists of fifty-seven lessons of twenty- to thirty-minute duration that are taught two to three times per week. A pretest-posttest control group design with random assignment of classrooms from schools in high-risk areas across sites in the United States has been conducted with over sixty-five hundred students from 198 intervention classrooms and 180 matched comparison classrooms (Conduct Problems Prevention Research Group, 1999). The findings reveal PATHS decreased aggression and hyperactive-disruptive behaviors and improved classroom atmosphere. Quality of program implementation (treatment integrity) was significantly related to decreases in teacher reports of classroom aggression and to improved classroom climate. In another investigation, one- and two-year longitudinal findings suggest that the PATHS curriculum may have lasting effects on emotional understanding and interpersonal social problem-solving skills (Greenberg and Kusche, 1996).

The Second Step Program is a classwide social skills program implemented by teachers for all preschool through middle school children (Grossman and others, 1997). The objective of the program is to teach students skills related to empathy, impulse control, and anger management. 
The program consists of thirty classroom lessons (each is approximately thirty-five to forty-five minutes in duration) typically taught one to two times per week. A pretest-posttest control group design with random assignment of schools to Second Step training versus control was conducted with 790 second and third graders (see Grossman and others, 1997). Students participating in Second Step were observed to exhibit less physical aggression and more prosocial behaviors than students in the control condition. Observations confirmed that treatment effects were largely maintained over a six-month period.

Additional research suggests that target populations may respond differently to Second Step. Broadbear (2001) found that children of divorce showed more decrease in negative conflict than children from intact marriages. And Washburn (2002) discovered that Second Step was particularly effective with low-income urban, minority students, although Taub's research (2002), which may have been hampered by inadequate sample size, found little positive impact on low-income, rural elementary school students. Finally, some studies fail to show any impact of Second Step (Botzer, 2003; Lillenstein, 2002), although program implementation fidelity is not established in these studies.

One study compared Second Step to a class-linked peer mediation program for third- and fourth-grade students (Harris, 1999). Classes were randomly assigned to treatment and control conditions. Teachers delivered the curricula over a semester. The results indicated no difference in effectiveness of the programs; however, there was a treatment by gender effect: boys performed better in the peer mediation class, and girls performed better in Second Step.

- Negotiation and general conflict curricula. Other than research concerning the TSPP program, which some consider to be a conflict curricula more than a peer mediation program, there is very little research on the effectiveness of general negotiation curricula. For example, Program for Young Negotiators (Nakkula and Nikitopoulos, 2001) is a popular program based on interests-based negotiation, but no studies were found that evaluated its effectiveness.

DuRant, Barkin, and Krowchuk (2001) report on a conflict curriculum used with low-income, minority sixth graders in four middle schools; intervention schools had 292 students and the control schools 412 students. The Peaceful Conflict Resolution and Violence Prevention Curriculum, a thirteen-module skills-building curriculum, taught identification of situations that could result in violence; avoidance, confrontation, 
problem-solving, and communication skills; conflict resolution skills; the conflict cycle; the dynamics of a fight; and how to express anger without fighting. The primary outcome variable was a five-item scale assessing the frequency of fighting and weapon-carrying behaviors and a scale measuring intentions to use violence in eleven hypothetical situations. From pretest to posttest, there was a decrease in the use of violence by students in the intervention group and an increase in the use of violence in the control group.

An innovative approach to delivering a conflict curriculum is through computer-generated lessons. Bosworth and her colleagues (2000) developed SMART talk, a computer-based intervention containing anger management and conflict-resolution modules. The 558 middle school students were randomly assigned to treatment or control groups and were assessed on self-awareness, attitudes toward violence, and intentions to use nonviolent strategies. SMART talk was successful in diminishing students' acceptance of violence and increased their intentions to use nonviolent strategies.

Three studies of conflict education curricula focus on urban minority populations. Heydenberk, Heydenberk, and Bailey (2003) implemented Project Peace, a teacher-delivered CRE program in fourth- and fifth-grade classes and evaluated the impacts on students' moral reasoning and attitudes about conflict (using Students Attitudes About Conflict [SAAC]). All treatment classrooms showed significant increases in moral reasoning ability and constructive conflict orientation. In a two-year study of the impact of a conflict education curriculum in middle and high school special-needs students (in an alternative disciplinary school), researchers found that the conflict curriculum had a significant impact on students' misconduct rates, hostile attribution, and aggressive orientation (Jones and Bodtker, 1999; Bodtker, 2001).

- Bullying prevention programs. In the past five years, many states have mandated bullying prevention programs (Title, 2003). School administrators and teachers search for effective curricula to stem the prevalence of bullying behavior (Lumsden, 2002). There is considerable research about bullying behaviors and consequences (Boulton, Trueman, and Flemington, 2002; Espelage and Swearer, 2003; Price, 2003) and teacher orientations to bullying (Craig, Henderson, and Murphy, 2000), but only three studies in the United States examine the efficacy of bullying prevention programs (and one of those is still in progress).

Instead of conducting the necessary research on these programs in U.S. contexts, educators and practitioners continue to refer to research 
conducted by Olweus in Norway (1991). This large-scale evaluation looked at the efficacy of the bullying program with Norwegian children ages eight to sixteen. The results indicate sustained (at least two years) reductions in school aggression (bullying was reduced by 50 percent), fighting, vandalism, alcohol abuse, and truancy. The effects were more pronounced the longer the program was in place. Other reports of effectiveness of the Bullying Prevention program have been forthcoming from Canada (Pepler, Craig, Ziegler, and Charach, 1994) and England (Whitney, Rivers, Smith, and Sharp, 1994). A study conducted by Melton and others (1998) in the United States was not obtainable. The only other study of an Olweus-based program in the United States was a process evaluation of program implementation (Price, 2003). Cunningham (2001) reports on a study in progress that will evaluate the Healthy Schools bullying prevention program in two urban middle schools, but results are pending.

Orpinas and Horne (2003) studied the application of the Peaceable Place program developed by the Mendez Foundation, a standard conflict education curriculum to teach $\mathrm{K}-5$ students conflict resolution skills, anger management, respect for self and others, and effective communication. There was a 40 percent reduction among younger children $(\mathrm{K}-2)$ in mean self-reported aggression and a 19 percent reduction in mean self-reported victimization. Among third through fifth graders there was a 23 percent reduction in mean reported victimization but no significant differences in self-reported aggression.

In her dissertation research, Kaiser-Ulrey (2004) evaluated the BEST (Bullying Eliminated from Schools Together) program developed for middle schools. One hundred twenty-five seventh-grade students were assigned in cohort groups to a treatment or comparison group. Teachers conducted the twelve-week intervention, which consisted of four basic modules including empathy and problem solving. The outcomes measured were bullying incidence, victimization incidence, empathy, prosocial behaviors, global self-esteem, and parental involvement. Results did not support any of the research hypotheses, except for an increase in social skills development of the treatment students.

Peaceable Classroom and Curriculum Integration. One of the most difficult aspects of CRE is finding a way for teachers to incorporate this while they address all the other pressures of mandated curricula and testing (Compton, 2002). Curriculum integration is often done in reading and language arts (Poliner, 2003), but can be done in any subject area. 
The National Curriculum Integration Project (NCIP) was a three-year study of curriculum infusion and integration in middle schools in four states (Compton, 2002; Jones and Sanford, 2003; Jones, Sanford, and Bodtker, 2001). A pretest-posttest control group comparison design in each state examined the effect of teaching condition (NCIP experienced teaching, NCIP new teaching, and control teaching) on over a thousand seventh- and eighth-grade students' emotional and conflict competence (conflict orientation, emotional management, perspective taking, and hostile attribution) and classroom climate. Although the NCIP conditions did not significantly influence emotional management, it did have positive impacts on students' perspective taking and use of problem-solving strategies. NCIP has extremely strong positive impacts on classroom climate. As expected, across sites, students in NCIP classes taught by returning, experienced NCIP teachers consistently reported more positive climate (overall and in terms of the dimensions of teacher support, student support, cohesion, safety, and constructive conflict management) than students in classes taught by new NCIP teachers. However, students in either NCIP class perceived a much more positive climate than students in control classes. NCIP impact on classroom climate increased throughout the year, while perceived climate in control classes usually became notably more negative throughout the year.

In terms of the teacher's integration of NCIP concepts into curriculum, when the goals of NCIP are clearly presented, there is strong evidence that teachers are capable of integrating these concepts and practices in their ongoing curricula. There is a learning curve for teachers; it takes sustained effort for a teacher to progress to optimal levels of integration and infusion. However, teachers can effectively mentor other teachers to achieve these levels. Teachers at most sites were able to develop complex and valuable integrated lessons for use in ongoing curricula (mostly English and language arts). While lessons in other disciplines were developed, it was more difficult, especially for the disciplines of math and science.

Peaceable School and Whole-School Programs. Few CRE efforts are truly whole school, and fewer still have been evaluated. One excellent study addresses peaceable school models in elementary schools, and two studies evaluate peaceable school models in middle schools.

At the elementary school level, Responding to Conflict Creatively Program (RCCP) has been the focus of an excellent evaluation (Aber, Brown, and Jones, 2003). RCCP includes teacher training, classroom 
instruction and staff development, program curriculum, administrators' training, peer mediation, parent training, and a targeted intervention for high-risk youth. RCCP is a complex, multiyear, multilevel CRE program (Selfridge, 2004). Four waves of data on features of children's social and emotional development known to forecast aggression and violence were collected in the fall and spring over two years for a representative sample of 11,160 first to sixth graders from New York City public schools. The results indicate that RCCP, when delivered as designed by the classroom teachers, had a significant impact on reducing attitudes and behaviors predictive of aggression and violence. Positive implications for orientation to academic achievement were also reported. Program fidelity was identified as a critical factor. Students in classes where teachers delivered some RCCP but not the amount or nature prescribed actually performed worse on dependent measures than control students.

The research at the middle school level shows mixed results. Orpinas and colleagues (2000) evaluated a multicomponent violence prevention intervention on reducing aggressive behaviors among students of eight middle schools randomly assigned to intervention or control conditions. The intervention included the formation of a school health promotion council, training of peer mediators and peer helpers, training of teachers in conflict resolution, a violence prevention curriculum, and newsletters for parents. All students were evaluated in the spring of 1994, 1995, and 1996 (approximately nine thousand students per evaluation). Sixth graders in 1994 were followed through seventh grade in 1995 or eighth grade in 1996 or both $(n=2,246)$. Cohort and cross-sectional evaluations indicated little to no intervention effect in reducing aggressive behaviors, fights at school, injuries due to fighting, missing classes because of feeling unsafe at school, or being threatened to be hurt. The Students for Peace experience suggests that interventions should begin prior to middle school, explore social and environmental intervention strategies, and involve parents and community members.

Shapiro and his colleagues (2002) evaluated a middle school CRE intervention (Peacebuilders Program) that trains all school staff to infuse CRE through all aspects of everyday school life. The program was implemented in three middle schools and three elementary schools with one control middle school and one control elementary school. Components of the Peacemakers Program are delivered initially by teachers and remedially by school psychologists and counselors. This study sampled almost two thousand students with pre- and postprogram assessment. There were significant, positive program effects on knowledge of psychosocial skills, 
self-reported aggression, teacher-reported aggression, a 41 percent decrease in aggression-related disciplinary incidents, and a 67 percent reduction in suspensions for violent behavior.

\section{Assessment and Direction}

Not so long ago, when administrators asked, "Does it work?" CRE practitioners had difficulty answering with convincing research evidence. That is no longer the case. This review clearly indicates that although there is more work to be done, the research clearly demonstrates that CRE approaches yield impressive results. The research on peer mediation, especially at elementary levels, confirms that mediators gain social and emotional competency from this experience and that schools can gain from improved classroom and school climate. Those impacts are much less evident with peer mediation in middle and high schools. The research on process curricula is either stunningly good or bad depending on the curricular area. Evidence for the efficacy of basic SEL programs and general conflict education programs is clear. Yet we need much more serious research attention to other curricular areas, especially bullying prevention. The research suggests that general CRE curricula may be effective in preventing bullying, but much more evidence is needed. And some very exciting new practice areas like dialogue, expressive arts, and restorative justice programs have yet to be evaluated rigorously in school settings. Curriculum integration research is solid but not sufficient in quantity or scope. We need replications of the National Curriculum Integration Project to continue to assess this complex process and its benefits. Finally, the whole-school program research, especially on RCCP, proves what many CRE practitioners have known for some time: the need is to address the whole system in a concerted, coordinated, integrated, and sustained effort to yield the most impressive results. It also suggests that a poorly implemented program may be worse than no program at all.

We should concentrate more on longitudinal analyses of CRE. The longest studies we have are three years in duration. But there are students who are potentially affected for life, with only short-term assessments of their experiences.

We need to develop ways of assessing the big questions about attainment of community, social justice, and caring environments. Our attention has been focused on important indicators of larger social objectives, but it is time to attend to the very difficult research tasks of assessing relational and system change. 
We must discontinue the emphasis on focusing on segments of CRE in schools that have a variety of potentially synergistic initiatives. We have a program mentality rather than a coordinated-practice mentality. Research goals and designs should be more focused on explaining CRE systems and components and studying their interaction, partial, and cumulative effects.

We should continue to define structural elements that bear on outcomes, enabling practitioners to suggest tailored interventions with reasonable certainty of their effectiveness. And we should attend to structural elements, especially issues of diversity of target population, that have received far too little research attention.

But even with the need for more research, it is clear that CRE programs have a great deal to offer children. The evidence supports Sandy and Cochran's conclusion (2000, p. 340): "Development in conflict resolution education and social-emotional learning skills is so critical to the education of our children that we must actively support infusion of this instruction throughout each child's educational experience, both in school and at home."

\section{References}

Aber, J. L., Brown, J. I., and Jones, S. M. "Developmental Trajectories Toward Violence in Middle Childhood: Course, Demographic Differences, and Response to School-Based Intervention.” Developmental Psychology, 2003, 39, 324-348.

Association for Conflict Resolution. School-Based Conflict Resolution Education Program Standards. Washington, D.C.: Association for Conflict Resolution, 2002.

Batton, J. "Institutionalizing Conflict Resolution Education: The Ohio Model." Conflict Resolution Quarterly, 2002, 19 (4), 479-494.

Bell, S. K., and others. "The Effectiveness of Peer Mediation in a Low-SES Rural Elementary School." Psychology in the Schools, 2000, 37, 505-516.

Bickmore, K. "Peer Mediation Training and Program Implementation in Elementary Schools: Research Results." Conflict Resolution Quarterly, 2002, 20, 137-160.

Bodine, R. J., and Crawford, D. K. The Handbook of Conflict Resolution Education: A Guide to Building Quality Programs in Schools. San Francisco: JosseyBass, 1998.

Bodtker, A. "Conflict Education and Special Needs Students, Part Two: Improving Conflict Competence and Emotional Competence." Conflict Resolution Quarterly, 2001, 18, 377-396.

Bosworth, K., and others. "Preliminary Evaluation of a Multi-Media Violence Prevention Program for Adolescents." American Journal of Health Behavior, 2000, 24 (4), 268-280. 
Botzer, E. A. "An Evaluation of the Effectiveness of the Second Step Violence Prevention Curriculum for Third Grade Students." Dissertation Abstracts International Section A: Humanities and Social Sciences, 2003, 64 (4-A), 1171.

Boulton, M. J., Trueman, M., and Flemington, I. "Associations Between Secondary School Pupils' Definitions of Bullying, Attitudes Towards Bullying, and Tendencies to Engage in Bullying: Age and Sex Differences." Educational Studies, 2002, 28, 133-156.

Broadbear, B. C. "Evaluation of the Second Step Curriculum for Conflict Resolution Skills in Preschool Children from Diverse Parent Households." Dissertation Abstracts International Section A: Humanities and Social Sciences, 2001, 61 (11-A), 4300.

Burrell, N. A., Zirbel, C. S., and Allen, M. "Evaluating Peer Mediation Outcomes in Educational Settings: A Meta-Analytic Review." Conflict Resolution Quarterly, 2003, 21 (1), 7-26.

Burstyn, J. N., and others. Preventing Violence in Schools: A Challenge to American Democracy. Mahwah, N.J.: Erlbaum, 2001.

Catalano, R. F., and others. "Positive Youth Development in the United States: Research Findings on Evaluations of Positive Youth Development Programs." Prevention and Treatment, 2000, 5. [http://journals.apa.org/ prevention/volume5/pre0050015a.html]. (Aug. 1, 2002).

Cohen, R. "Students Helping Students: Peer Mediation." In T. Jones and R. Compton (eds.), Kids Working It Out: Stories and Strategies for Making Peace in Our Schools. San Francisco: Jossey-Bass, 2003.

Compton, R. "Discovering the Promise of Curriculum Integration: The National Curriculum Integration Project.” Conflict Resolution Quarterly, 2002, 19, 447-165.

Conduct Problems Prevention Research Group. "Initial Impact of the Fast Track Prevention Trial of Conduct Problems: II. Classroom Effect." Journal of Consulting and Clinical Psychology, 1999, 67, 648-657.

Conte, Z. "The Gift of the Arts." In L. Lantieri (ed.), Schools with Spirit: Nurturing the Inner Lives of Children and Teachers. Boston: Beacon Press, 2001.

Craig, W., Henderson, K., and Murphy, J. "Prospective Teachers' Attitudes Toward Bullying and Victimization." School Psychology International, 2000, 21 (1), 5-22.

Crosse, S., and others. Wide Scope: Questionable Quality: Three Reports from the Study on School Violence and Prevention. Washington, D.C.: Department of Education, 2002.

Cuervo, A. G. "Postscript: The Importance of Supporting Conflict Resolution Education." In T. Jones and R. Compton (eds.), Kids Working It Out: Stories and Strategies for Making Peace in Our Schools. San Francisco: Jossey-Bass, 2003.

Cunningham, P. B. "Implementation of an Empirically Based Drug and Violence Prevention and Intervention Program in Public School Settings." Journal of Clinical Child Psychology, 2001, 30 (2), 221-233. 
Druliner, J. K., and Prichard, H. "'We Can Handle This Ourselves': Learning to Negotiate Conflicts." In T. Jones and R. Compton (eds.), Kids Working It Out: Stories and Strategies for Making Peace in Our Schools. San Francisco: Jossey-Bass, 2003.

Dudley, B. S. "Peer Mediation and Negotiation in the Middle School: An Investigation of Training Effects." Dissertation Abstracts International Section A: Humanities and Social Sciences, 1995, 56 (1-A), 0142.

Dudley, B. S., Johnson, D. W., and Johnson, R. "Conflict-Resolution Training and Middle School Students' Integrative Negotiation Behavior." Journal of Applied Social Psychology, 1996, 26, 2038-2052.

DuRant, R., Barkin, S., and Krowchuk, D. "Evaluation of a Peaceful Conflict Resolution and Violence Prevention Curriculum for Sixth-Grade Students." Journal of Adolescent Health, 2001, 28, 386-393.

Elias, M. J., and others. Promoting Social and Emotional Learning: Guidelines for Educators. Alexandria, Va.: Association for Supervision and Curriculum Development, 1997.

Epstein, E. "Evaluation of an Elementary School Conflict Resolution-Peer Mediation Program." Dissertation Abstracts International Section A: Humanities and Social Sciences, 1996, 57 (6-A), 2370.

Espelage, D. L., and Swearer, S. "Research on School Bullying and Victimization: What Have We Learned and Where Do We Go from Here?" School Psychology Review, 2003, 32, 365-384.

Farrell, A. D., Meyer, A., Kung, E., and Sullivan, T. "Development and Evaluation of School-Based Violence Prevention Programs." Journal of Clinical Child Psychology, 2001, 30 (2), 207-221.

Farrell, A. D., Meyer, A. L., and White, K. S. "Evaluation of Responding in Peaceful and Positive Ways (RIPP): A School-Based Prevention Program for Reducing Violence Among Urban Adolescents." Journal of Clinical Child Psychology, 2001, 30, 451-464.

Farrell, A. D., Valois, R., and Meyer, A. "Evaluations of the RIPP-6 Violence Prevention at a Rural Middle School." American Journal of Health Education, 2002, 33 (3), 167-172.

Fast, J., Fanelli, F., and Salen, L. "How Becoming Mediators Affects Aggressive Students." Children and Schools, 2003, 25, 161-171.

Feiman-Nemser, S. "What New Teachers Need to Learn." Educational Leadership, 2003, 60 (8), 25-30.

Fitch, T., and Marshall, J. L. The Teaching Students to Be Peacemakers Program: Program Overview and Review of the Literature. 1999. (ED 436 517)

Ford, E. "Oregon's SCRIP Model: Building School Conflict Resolution Education Capacity Through Community Partnerships." Conflict Resolution Quarterly, 2002, 19, 465-477.

Gentry, D. B., and Benenson, W. "School-Age Peer Mediators Transfer Knowledge and Skills to Home Setting." Mediation Quarterly, 1992, 10, 101-109.

Girard, K., and Koch, S. Conflict Resolution in the Schools: A Manual for Educators. San Francisco: Jossey-Bass, 1996. 
Greenberg, M. T., and Kusche, C. A. The PATHS Project: Preventive Intervention for Children. Final Report to the National Institute of Health. Seattle: University of Washington, 1996.

Greenberg, M. T., and others. "Enhancing School-Based Prevention and Youth Development Through Coordinated Social, Emotional and Academic Learning." American Psychologist, 2003, 58, 466-474.

Grossman, D. C., and others. "Effectiveness of a Violence Prevention Curriculum Among Children in Elementary School: A Randomized Controlled Trial." Journal of the American Medical Association, 1997, 277, 1605-1611.

Harris, I. M., and Morrison, M. L. Peace Education. (2nd ed.). Jefferson, N.C.: McFarland, 2003.

Harris, P. "Teaching Conflict Resolution Skills to Children: A Comparison Between a Curriculum Based and a Modified Peer Mediation Program." Dissertation Abstracts International, Section A: Humanities and Social Sciences, 1999, 59 (9-A), 3397.

Hart, J., and Gunty, M. "The Impact of a Peer Mediation Program on an Elementary School Environment." Peace and Change, 1997, 22 (1), 76-92.

Heerboth, J. P. "School Violence Prevention Programs in Southern Illinois High Schools: Factors Related to Principals' and Counselors' Perceptions of Success." Dissertation Abstracts International, Section A: Humanities and Social Sciences, 2000, 60 (8-A), 2752.

Heydenberk, W., Heydenberk, R., and Bailey, S. "Conflict Resolution and Moral Reasoning." Conflict Resolution Quarterly, 2003, 21 (1), 27-46.

Hoy, W. K., Tarter, C. J., and Kottkamp., R. B. Open School/Health Schools: Measuring Organizational Climate. Thousand Oaks, Calif:: Sage, 1991.

Ierley, A., and Claassen-Wilson, D. "Making Things Right: Restorative Justice for School Communities." In T. Jones and R. Compton (eds.), Kids Working It Out: Stories and Strategies for Making Peace in Our Schools. San Francisco: Jossey-Bass, 2003.

Johnson, D., and others. "The Impact of Peer Mediation Training on the Management of School and Home Conflicts." American Educational Research Journal, 1995, 32, 829-444.

Johnson, D. W., and Johnson, R. T. "Conflict Resolution and Peer Mediation Programs in Elementary and Secondary Schools: A Review of the Research." Review of Educational Research, 1996a, 66, 459-506.

Johnson, D. W., and Johnson, R. "Effectiveness of Conflict Managers in an Inner-City Elementary School." Journal of Educational Research, 1996b, 89, 280-286.

Johnson, D. W., and Johnson, R. "Training Elementary School Students to Manage Conflict." Journal of Group Psychotherapy, 1996c, 49 (1), 24-39.

Johnson, D. W., and Johnson, R. "The Impact of Conflict Resolution Training on Middle School Students." Journal of Social Psychology, 1997, 137 (1), 11-22.

Johnson, D. W., and Johnson, R. T. "Teaching Students to Be Peacemakers: A Meta-Analysis." Paper presented at the Annual Meeting of the American Educational Research Association, Seattle, Wash., Apr. 10-14, 2001 a. 
Johnson, D. W., and Johnson, R. "Peer Mediation in an Inner City School." Urban Education, 2001b, 36 (2), 165-179.

Johnson, D. W., Johnson, R. T., and Tjosvold, D. "Constructive Controversy: The Value of Intellectual Opposition.” In M. Deutsch and P. Coleman (eds.), The Handbook of Conflict Resolution. San Francisco: Jossey-Bass, 2000.

Johnson, D. W., and others. "Using Conflict Managers to Mediate Conflicts in an Inner-City Elementary School.” Mediation Quarterly, 1995, 12 (4), 379-390.

Jones, T. S., and Bodtker, A. "Conflict Education in a Special Needs Population." Mediation Quarterly, 1999, 17, 109-124.

Jones, T. S., and Brinkman, H. "Teach Your Children Well: Recommendations for Peer Mediation Programs." In J. Folger and T. Jones (eds.), New Directions in Mediation: Communication Research and Perspectives (pp. 159-174). Beverly Hills: Sage, 1994.

Jones, T. S., and Compton, R. Kids Working It Out: Stories and Strategies for Making Peace in Our Schools. San Francisco: Jossey-Bass, 2003.

Jones, T. S., and Kmitta, D. (eds.). Does It Work? The Case for Conflict Education in Our Nation's Schools. Washington, D.C.: Conflict Resolution Education Network, 2000. [www.acresolution.org].

Jones, T. S., and Sanford, R. "Building the Container: Curriculum Infusion and Classroom Climate." Conflict Resolution Quarterly, 2003, 21 (1), 115-130.

Jones, T. S., Sanford, R., and Bodtker, A. The National Curriculum Integration Project: Research Report. Philadelphia: Temple University, 2001.

Jones, T. S., and others. Preliminary Final Report of the Comprehensive Peer Mediation Evaluation Project. Philadelphia: Temple University, College of Allied Health Professions, 1997.

Juvonen, J., and Graham, S. Peer Harassment in School: The Plight of the Vulnerable and Victimized. New York: Guilford Press, 2001.

Kaiser-Ulrey, C. L. "Bullying in Middle School: A Study of B.E.S.T.-Bullying Eliminated from Schools Together: An Anti-Bullying Program for SeventhGrade Students." Dissertation Abstracts International, Section B: Sciences and Engineering, 2004, 64 (7-B), 2004.

Kessler, R. "The Heart of the Matter: Social and Emotional Learning as a Foundation for Conflict Resolution Education." In T. Jones and R. Compton (eds.), Kids Working It Out: Stories and Strategies for Making Peace in Our Schools. San Francisco: Jossey-Bass, 2003.

King, K. A., Wagner, D. I., and Hedrick, B. "Safe and Drug Free School Coordinators' Perceived Needs to Improve Violence and Drug Prevention Programs." Journal of School Health, 2001, 71 (6), 236-242.

Kohn, A. Beyond Discipline: From Compliance to Community. Alexandria, Va.: Association for Supervision and Curriculum Development, 1996.

Korn, J. Increasing Teachers' and Students' Skill Levels of Conflict Resolution and Peer Mediation Strategies through Teacher and Student Training Programs. 1994. (ED 375 944)

Kusche, C. A., and Greenberg, M. T. The PATHS Curriculum. Seattle: Developmental Research and Programs, 1995. 
Lane-Garon, P. "Practicing Peace: The Impact of a School-Based Conflict Resolution Program on Elementary Students." Peace and Change, 2000, 25, 467-483.

Lane-Garon, P., and Richardson, T. "Mediator Mentors: Improving School Climate, Nurturing Student Disposition." Conflict Resolution Quarterly, 2003, 21 (1), 47-68.

Lane-Garon, P. S. "Developmental Considerations: Encouraging PerspectiveTaking in Student Mediators." Mediation Quarterly, 1998, 16 (2), 201-217.

Lantieri, L. (ed.). Schools with Spirit: Nurturing the Inner Lives of Children and Teachers. Boston: Beacon Press, 2001.

Lantieri, L., and Patti, J. Waging Peace in Our Schools. Boston: Beacon Press, 1996.

Lieber, C. M. "The Building Blocks of Conflict Resolution Education: Direct Instruction, Adult Modeling, and Core Practices." In T. Jones and R. Compton (eds.), Kids Working It Out: Stories and Strategies for Making Peace in Our Schools. San Francisco: Jossey-Bass, 2003.

Lillenstein, J. A. "Efficacy of a Social Skills Training Curriculum with Early Elementary Students in Four Parochial Schools." Dissertation Abstracts International Section A: Humanities and Social Sciences, 2002, 62 (9-A), 29712.

Lumsden, L. Preventing Bullying. 2002. (ED D00 036)

Lupton-Smith, H. S. "The Effects of a Peer Mediation Training Program on High School and Elementary School Students." Dissertation Abstracts International Section A: Humanities and Social Sciences, 1996, 57 (2-A), 0589.

Mankopf, J. F. "The Effects of Being a Peer Mediator on Adolescents' PerspectiveTaking and Connectedness." Dissertation Abstracts International Section A: Humanities and Social Sciences, 2003, 63 (11-A), 3866.

Melton, G. B., and others. Violence Among Rural Youth. Washington, D.C.: U.S. Department of Justice, 1998.

Meyer, R. H. "The Effect of Participation in a Peer Mediation Program on the Self-Perceptions and Conflict Style of At-Risk Elementary Students." Dissertation Abstract International Section A: Humanities and Social Sciences, 1996, 56 (9-A), 3457.

Miller, P. H. "The Relative Effectiveness of Peer Mediation: Children Helping Each Other to Solve Conflicts." Dissertation Abstracts International Section A: Humanities and Social Sciences, 1995, 55 (7-A), 1880.

Nakkula, M., and Nikitipoulos, C. "Negotiation Training and Interpersonal Development: An Exploratory Study of Early Adolescents in Argentina." Adolescence, 2001, 36 (4), 1-21.

Nance, T. M. "Impact of the Peer Mediation Component of the New Mexico Center for Dispute Resolution Mediation in the Schools Program." Dissertation Abstracts International Section A: Humanities and Social Sciences, 1996, 56 (9-A), 3512.

Nelson, K. D. "The Effects of Peer Mediation Training and Practice on SelfEsteem and Social Skills Among Peer Mediators in a Vocational Technical High School." Dissertation Abstracts International Section A: Humanities and Social Sciences, 1997, 58 (6-A), 2073. 
Nelson-Haynes, L. "The Impact of the Student Conflict Resolution Program in Dallas Public Schools." Dissertation Abstracts International Section A: Humanities and Social Sciences, 1996, 56 (9-A), 3458.

Olweus, D. "Bully/Victim Problems Among School Children: Basic Facts and Effects of a School-Based Intervention Program.” In D. J. Pepler and K. H. Rubin (eds.), The Development and Treatment of Childhood Aggression. Mahwah, N.J.: Erlbaum, 1991.

Oppitz, J. L. "Violence Prevention: Empowering School Counselors-A Study of Strategies Used by Practicing Elementary School Counselors." Dissertation Abstracts International, Section A: Humanities and Social Sciences, 2003, 63 (8-A), 2800.

Orpinas, P., and Horne, A. M. "School Bullying: Changing the Problem by Changing the School." School Psychology Review, 2003, 32 (3), 431-445.

Orpinas, P., and others. "Outcome Evaluation of a Multi-Component Violence Prevention Program for Middle Schools: The Students for Peace Project.” Health Education Research, 2000, 15 (1), 45-58.

Oskamp, S. Reducing Prejudice and Discrimination. Mahwah, N.J.: Erlbaum, 2000.

Pepler, D. J., Craig, W. M., Ziegler, S., and Charach, A. "An Evaluation of an Anti-Bullying Intervention in Toronto Schools." Canadian Journal of Community Mental Health, 1994, 13, 95-110.

Pettigrew, T. F., and Tropp, L. R. "Does Intergroup Contact Reduce Prejudice? Recent Meta-Analytic Findings.” In S. Oskamp (Ed.), Reducing Prejudice and Discrimination. Mahwah, N.J.: Erlbaum, 2000.

Poliner, R. "Making Meaningful Connections: Curriculum Infusion." In T. Jones and R. Compton (eds.), Kids Working It Out: Stories and Strategies for Making Peace in Our Schools. San Francisco: Jossey-Bass, 2003.

Potts, K. L. "The Relationship Between the Quality and Number of Interpersonal Negotiation Strategies and Coping Styles of High School Students with and Without Peer Mediation Training." Dissertation Abstracts International Section A: Humanities and Social Sciences, 2002, 62 (11-A), 3692.

Price, R. H. "Systems Within Systems: Putting Program Implementation in Organizational Context." Prevention and Treatment, 2003, 6, 1-14.

Prutzman, P. "R.E.S.P.E.C.T.: Appreciating and Welcoming Differences." In T. Jones and R. Compton (eds.), Kids Working It Out: Stories and Strategies for Making Peace in Our Schools. San Francisco: Jossey-Bass, 2003.

Robinson, T. R., Smith, S. W., and Daunic, A. P. "Middle School Students' Views on the Social Validity of Peer Mediation." Middle School Journal, 2000, 31 (5), 23-29.

Salomon, G. "The Nature of Peace Education: Not All Programs Are Created Equal." In G. Salomon and B. Nevo (eds.), Peace Education: The Concept, Principles and Practices Around the World. Mahwah, N.J.: Erlbaum, 2002.

Sandy, S. V., and Boardman, S. K. "The Peaceful Kids Conflict Resolution Program.” International Journal of Conflict Management, 2000, 11, 337-357. 
Sandy, S. V., and Cochran, K. "The Development of Conflict Resolution Skills in Children: Preschool to Adolescence." In M. Deutsch and P. Coleman (eds.), The Handbook of Conflict Resolution: Theory and Practice. San Francisco: Jossey-Bass, 2000.

Selfridge, J. "The Resolving Conflict Creatively Program: How We Know It Works." Theory into Practice, 2004, 43 (1), 59-68.

Selman, R. The Growth of Interpersonal Understanding. New York: Academic Press, 1980.

Shann, M. H. "Professional Commitment and Satisfaction Among Teachers in Urban Middle School." Journal of Educational Research, 1998, 92 (2), $67-74$.

Shapiro, D. "Editors' Notes." In D. L. Shapiro and B. E. Clayton (eds.), Negotiation-Interpersonal Approaches to Intergroup Conflict. New Directions in Youth Development, no. 102. San Francisco: Jossey-Bass, 2004.

Shapiro, J. P., and others. "Evaluation of the Peacemakers Program: School-Based Violence Prevention for Students in Grades Four Through Eight.” Psychology in the Schools, 2002, 39 (1), 87-100.

Smith, S. N., and Fairman, D. "Normalizing Effective Conflict Management Through Academic Curriculum Integration: The Example of Workable Peace.” In D. L. Shapiro and B. E. Clayton (eds.), Negotiation-Interpersonal Approaches to Intergroup Conflict. New Directions for Youth Development, no. 102. San Francisco: Jossey-Bass, 2004.

Smith, S. W., Daunic, A., Miller, M., and Robinson, T. "Conflict Resolution and Peer Mediation in Middle Schools: Extending the Process and Outcome Knowledge Base." Journal of Social Psychology, 2002, 142, 567-587.

Sommers, M. "Peace Education: Opportunities and Challenges." Presentation at the Building Bridges to Peace and Prosperity: Education and Training for Action, U.S. Agency for International Development, Washington, D.C., Aug. 11-15, 2003.

Stevahn, L. "Integrating Conflict Resolution Training into the Curriculum." Theory into Practice, 2004, 43 (1), 50-63.

Stevahn, L., Johnson, D. W., Johnson, R. T., and Schultz, R. "Effects of Conflict Resolution Training Integrated into a High School Social Studies Curriculum." Journal of Social Psychology, 2002, 142 (3), 305-333.

Stewart, J. "A Special Edition on Educational Programs in Juvenile Correctional Facilities." Journal of Correctional Education, 2002, 53 (2), 24-35.

Stewart, J. T. "A Formative Evaluation of a Conflict Resolution Program Utilizing Peer Mediation Training on the Knowledge and Attitudes of Middle School Students at a Hillsborough County, Florida, Middle School.” Dissertation Abstracts International Section A: Humanities and Social Sciences, 2000, 60 (12-A), 4374.

Sweeney, B. C. "Peer Mediation Training: Developmental Effects for High School Mediators." Dissertation Abstracts International Section A: Humanities and Social Sciences, 1996, 56 (11-A), 4285. 
Taub, J. "Evaluation of the Second Step Violence Prevention Program at a Rural Elementary School." School Psychology Review, 2002, 31, 186-200.

Title, B. B. "School Bullying: Prevention and Intervention." In T. Jones and R. Compton (eds.), Kids Working It Out: Stories and Strategies for Making Peace in Our Schools. San Francisco: Jossey-Bass, 2003.

Tolson, E. R., and McDonald, S. "Peer Mediation Among High School Students: A Test of Effectiveness." Social Work in Education, 1992, 14 (2), 86-94.

Tschannen-Moran, M. "The Effects of a State-Wide Conflict Management Initiative in Schools." American Secondary Education, 2001, 29 (3), 2-32.

U.S. Department of Education. Violence and Discipline Problems in U.S. Public Schools 1996-1997. Washington, D.C.: U.S. Department of Education, 1998.

U.S. Office of the Surgeon General. Youth Violence: A Report of the Surgeon General. Washington, D.C.: U.S. Department of Health and Human Services, 2001.

Warters, W. C. "Conflict Management in Higher Education: A Review of Current Approaches." In S. A. Holton (ed.), Conflict Management in Higher Education. New Directions for Higher Education, no. 92. San Francisco: Jossey-Bass, 1995.

Warters, W. C. Mediation in the Campus Community: Designing and Managing Effective Programs. San Francisco: Jossey-Bass, 2000.

Washburn, J. J. "Evaluation of a Violence Prevention Program with Low-Income, Urban, African-American Youth.” Dissertation Abstracts International Section B: Sciences and Engineering, 2002, 62 (9-B), 4242.

Weissberg, R. P., and Greenberg, M. T. "School and Community Competence Enhancement and Prevention Programs." In I. E. Siegel and K. A. Renninger (eds.), Handbook of Child Psychology, Vol. 4: Child Psychology in Practice. (5th ed.) New York: Wiley, 1998.

Whitney, I., Rivers, I., Smith, P. K., and Sharp, S. “The Sheffield Project: Methodology and Findings." In P. K. Smith and S. Sharp (eds.), School Bullying: Insights and Perspectives. London: Routledge, 1994.

Whittall, S. T. "School's Out: Time for Fun, Relaxation, and Peaceful Conflict Resolution Education." In T. Jones and R. Compton (eds.), Kids Working It Out: Stories and Strategies for Making Peace in Our Schools. San Francisco: Jossey-Bass, 2003.

Wilson, D. B., Gottfredson, D. C., and Najaka, S. S. "School-Based Prevention of Problem Behaviors: A Meta-Analysis." Journal of Quantitative Criminology, 2001, 17, 247-276.

Winston, M. L. "Assessing the Effects of a Peer Mediation Training Program on Skills Acquisition, Maintenance, and Generalization." Dissertation Abstracts International Section A: Humanities and Social Sciences, 1997, 57(7-A), 2863.

Zins, J. E., Weissberg, R. P., Wang, M. C., and Walberg, H. J. (eds.). Building School Success Through Social and Emotional Learning. New York: Teachers College Press, 2004. 
Zucca-Brown, S. "An Elementary School Mediation Program: Its Effect on Student Mediators and School Violence." Dissertation Abstracts International Section A: Humanities and Social Sciences, 1997, 58 (6-A), 2077.

Tricia S. Jones is a professor in the Department of Psychological Studies in the College of Education, Temple University in Philadelphia. Jones is the past president (1996-1997) of the International Association of Conflict Management. She currently serves as the editor-in-chief of Conflict Resolution Quarterly. 